\title{
EFEK BERGANDA (MULTIPLIER EFFECT) PT. HUTAN KETAPANG INDUSTRI TERHADAP USAHA MASYARAKAT DUSUN SILINGAN DAN DUSUN KLUKUBLANTAK DESA MEKAR UTAMA KECAMATAN KENDAWANGAN KABUPATEN KETAPANG
}

(Multiplier Effect Pt. Hutan Ketapang Industri Towards The Community Business In Silingan Hamlet And Klukublantak Hamlet In The Mekar Utama Village Of Kendawangan Subdistrict Ketapang District)

Jimi Rahadi, Emi Roslinda, M. Idham.

Fakultas Kehutanan Universtas Tanjungpura Pontianak. Jl. Daya Nasional Pontianak 78124

Email: jimirahadi6@gamail.com

\begin{abstract}
Industrial plantations (HTI) are plantations established by industrial groups to increase the potential and quality of production forests by implementing silvicultural systems in order to meet the needs of raw materials. PT. HKI is one of the HTI engaged in the industry which is located in Silingan and Klukublantak sub-villages, Mekar Utama Village, Kendawangan District. The existence of PT. HKI impacts business actors, workers, and the community around the PT. HKI. Therefore it is necessary to analyze the economic impact caused by PT. HKI. The purpose of this study is to examine the characteristics and perceptions of business people, workers, and the community, and examine the multiplier effect on the existence of PT. HKI. This research uses the respondent sampling method with quota sampling technique. Respondents in this study were 90 people divided into 30 business people, 30 workers, and 30 people. Data analysis uses descriptive analysis and multiplier effect analysis of the characteristics of business people, workers, and the public in PT. HKI. Characteristics of respondents in PT. HKI is dominated by men. The perception of business people, workers, and the community tends to be positive. The economic impact can be seen from the Keynesian Income Multiplier value obtained at 3.25 while the Type 1 Multiplier Income Ratio is 1.19 and the Type 2 Multiplier Income Ratio is 1.29. Based on this it can be concluded that PT. HKI provides an economic impact on businesses and workers in the area of PT. HKI.
\end{abstract}

Keywords: Characteristics, Multiplier effect, Perception.

\section{PENDAHULUAN}

Hutan tanaman industri adalah hutan produksi yang dibangun oleh kelompok industri untuk meningkatkan potensi dan kualitas hutan dengan menerapkan sistem silvikultur dalam rangka memenuhi kebutuhan bahan baku industri. HTI bertujuan memberikan dampak positif terhadap ekonomi, sosial, dan lingkungan masyarakat (Kementrian Kehutanan, 2008). Keberadaan HTI diduga dapat menimbulkan multiplier effect terhadap pendapatan masyarakat disekitar kawasan. Menurut Sholihin (2010), multiplier effect adalah dampak suatu industri dalam bentuk peningkatan pendapatan masyarakat, keseimbangan exploitasi dan sumberdaya yang akan semakin berkembang dalam kehidupan sosial ekonomi masyarakat. Menurut Sukirno (2012), multiplier effect merupakan suatu 
kegiatan yang akan memicu timbulnya kegiatan lain.

PT. HKI berlokasi di Kecamatan Kendawangan Kabupaten Ketapang Provinsi Kalimantan Barat dengan membuka hutan tanaman industri karet dengan luas yang sudah tertanam saat ini sekitar 9.000 ha dengan total lahan 100.000 ha, salah satu tujuan pembukaan lahan kebun karet ini untuk meningkatkan ekonomi masyarakat disekitar kebun karet. Rata-rata pekerja adalah masyarakat setempat, dan pekerja dari luar daerah. PT. HKI ini berdampak pada pendapatan masyarakat disekitar, khususnya masyarakat yang meiliki usaha dan yang bekerja di PT. HKI. Hal ini sesuai dengan teori multiplier effect yang menyatakan bahwa perkembangan industri dapat meningkatkan pendapatan masyarakat yang berlipat ganda (Hasanah, 2012). Tujuan penelitian ini adalah mengkaji karakteristik pelaku usaha, tenaga kerja dan masyarakat; mengkaji karakteristik jenis usaha. mengkaji persepsi pelaku usaha tenaga kerja dan masyarakat terhadap keberadaan PT. HKI; mengkaji multiplier effect PT. HKI terhadap jenis usaha masyarakat di Dusun Silingan dan Klukublantak Desa Mekar Utama.

\section{METODE PENELITIAN}

Penelitian dilaksanakan di Dusun Silingan dan Dusun Klukublantak Desa Mekar Utama pada tanggal 30 januari 2019 selama 3 minggu. Metode pengumpulan data dilakukan dengan teknik wawancara menggunakan alat kuesioner yang diajukan kepada responden. Subjek penelitian ini adalah pelaku usaha, tenaga kerja dan masyarakat dan objek penelitian ini adalah usaha masyarakat yang ada di Dusun Silingan dan Dusun Klukublantak. Pengambilan sample dilakukan menggunakan tehnik metode quota sampling dengan cara menetapkan jumlah tertentu (Sugiyono, 2003). Jumlah responden yang dibutuhkan sebanyak 90 orang.

Tabel 1. Ringkasan Metode Penelitian (Summary of Research Methods)

\begin{tabular}{|c|c|c|c|c|}
\hline No & Tujuan Penelitian & Sumber Data & Variabel & Analisis Data \\
\hline 1 & $\begin{array}{l}\text { Mengkaji karakteristik } \\
\text { Pelaku Usaha, Tenaga } \\
\text { Kerja dan Masyarakat } \\
\text { Dusun Silingan dan Dusun } \\
\text { Klukublantak }\end{array}$ & $\begin{array}{l}\text { Data Primer dengan } \\
\text { Wawancara Menggunkan } \\
\text { Kuesioner. }\end{array}$ & $\begin{array}{l}\text { Karakteristik: usia, jenis } \\
\text { kelamin, pendidikan } \\
\text { terkahir, pendapatan, } \\
\text { pengeluaran daerah asal, } \\
\text { setatus, lama berusaha, } \\
\text { jenis usaha, lama bekerja }\end{array}$ & $\begin{array}{l}\text { Analisis Deskriptip } \\
\text { Persentase }\end{array}$ \\
\hline 2 & $\begin{array}{l}\text { Mengkaji persepsi pelaku } \\
\text { usaha,tenaga } \\
\text { kerja dan masyarakat } \\
\text { terhadap keberadaan } \\
\text { PT. HKI. }\end{array}$ & $\begin{array}{l}\text { Data Primer dengan } \\
\text { Wawancara } \\
\text { Menggunkan } \\
\text { Kuesioner. }\end{array}$ & $\begin{array}{l}\text { Persepsi:Pentingnya } \\
\text { Keberadaan PT. } \\
\text { HKIpeningkatan } \\
\text { pendapatan, peluang } \\
\text { usaha, peluang bekerja, } \\
\text { sarana dan prasarana } \\
\text { meningkatkan } \\
\text { kesejahteraan hidup, } \\
\text { dampak positif, taraf } \\
\text { hidup, pekeja pendatang. }\end{array}$ & $\begin{array}{l}\text { Analisis Deskriptip } \\
\text { Chi Square }\end{array}$ \\
\hline 3 & $\begin{array}{l}\text { Mengkaji Multiplier } \\
\text { effect PT. HKI terhadap } \\
\text { jenis usaha masyarakat }\end{array}$ & $\begin{array}{l}\text { Data Primer dengan } \\
\text { Wawancara } \\
\text { Menggunkan } \\
\text { Kuesioner. }\end{array}$ & $\begin{array}{l}\text { Etsimasi } \\
\text { pengeluaran responden } \\
\text { untuk konsumsi di } \\
\text { kawasan PT. HKI. }\end{array}$ & $\begin{array}{l}\text { Metode analisis multiplier } \\
\text { effect }\end{array}$ \\
\hline
\end{tabular}




\begin{tabular}{|c|c|c|}
\hline No & Tujuan Penelitian & Analisis Data \\
\hline & & $\begin{array}{l}\text { - Etsimasi pendapatan } \\
\text { pelaku usaha dari } \\
\text { pengeluaran masyarakat } \\
\text { dan pekerja dari luar } \\
\text { - Etsimasi pendapatan } \\
\text { dan pengeluaran tenaga } \\
\text { kerja: upah }\end{array}$ \\
\hline
\end{tabular}

Analisis deskriptif Dengan menggunakan rumus Confidence Interval (CI) dimana dengan tingkat kepercayaan 95\% .

Positif, jika persepsi masyarakat $>\bar{x}+$ t.sx

Netral, jika persepsi masyarakat antara $\bar{x}-t . s x$ s/d $\bar{x}+t . s x$

Negatif, jika persepsi $<\bar{x}-t . s x$

Keterangan :

$\overline{\boldsymbol{x}}=$ Rata-rata

$t=\mathrm{t}$ tabel

$s x=$ Standar error

Uji Statistik Deskriptif (Uji Chi Square) satu sampel dengan tiga kategori dengan rumus sebagai berikut :

$X^{2}=\sum_{i=1}^{K} \frac{\left(f_{0}-f_{h}\right)^{2}}{f_{h}}$

Dimana:

$x^{2}=$ chi-kuadrat

$f_{0} \quad=$ frekuensi yang diobsevasi

$f_{h} \quad=$ frekuensi yang diharapkan

Ketentuan dalam pengujian hipotesis menggunakan analisis Chi-kuadrat yaitu jika nilai Chi-kuadrat hitung lebih kecil $(<)$ dari nilai Chi-kuadrat tabel, maka tidak terdapat perbedaan frekuensi persepsi. Akan tetapi sebaliknya jika nilai Chikuadrat hitung lebih besar atau sama dengan harga tabel maka terdapat perbedaan frekuensi persepsi.

Analisis efek berganda ini dapat diukur dengan menggunakan efek pengganda atau multiplier effect dari keadaan di lapangan (Anissa, 2013).

Secara matematis dirumuskan :

Keynesian Income Multiplier $=\frac{\mathrm{D}+\mathrm{N}+\mathrm{U}}{\mathrm{E}}$

Ratio Income Multiplier, Tipe $\mathrm{I}=\frac{\mathrm{D}+\mathrm{N}}{\mathrm{D}}$

Ratio Income Multiplier, Tipe $\mathrm{II}=\frac{\mathrm{D}+\mathrm{N}+\mathrm{U}}{\mathrm{D}}$ dimana :

E : pengeluaran unit usaha (Rupiah)

D : pendapatan yang diperoleh secara langsung (pelaku usaha)

$\mathrm{N}$ : pendapatan yang diperoleh secara tidak langsung (tenaga kerja)

$\mathrm{U}$ : pendapatan yang diperoleh secara induced

Nilai Keynesian Local Income Multiplier, Ratio Income Multiplier Tipe I, Ratio Income Multiplier Tipe II memiliki kriteria-kriteria sebagai berikut:

1. Apabila nilai-nilai tersebut kurang dari atau sama dengan nol $(\leq 0)$, maka lokasi PT. HKI tersebut belum mampu memberikan dampak ekonomi terhadap kegiatan usahanya.

2. Apabila nilai-nilai tersebut diantara angka nol dan satu $(0<\mathrm{x}<1)$, maka lokasi PT. HKI tersebut masih memiliki nilai dampak ekonomi yang rendah, dan

3. Apabila nilai-nilai tersebut lebih besar atau sama dengan satu $(\geq 1)$, maka lokasi PT. HKI tersebut telah mampu 
memberikan dampak ekonomi terhadap kegiatan usaha masyarakat.

\section{HASIL DAN PEMBAHASAN}

karakteristik pelaku usaha, tenaga kerja dan masyarakat di kawasan PT. HKI didominasi oleh laki-laki sedangkan karakteriktik jenis usaha, jenis usaha masyarakat yang paling banyak yaitu warung sembako dengan proporsi 46,67\%. Hasil dari Persepsi pelaku usaha, tenaga kerja dan masyarakat terhadap keberadaan PT. HKI di Dusun Silingan dan Dusun Klukublantak cendrung positif. dapat di lihat dari tabel berikut:

Table 2. Persepsi Pelaku Usaha Terhadap Keberadaan PT. HKI (Business Actors Perception of the Existence of PT. HKI)

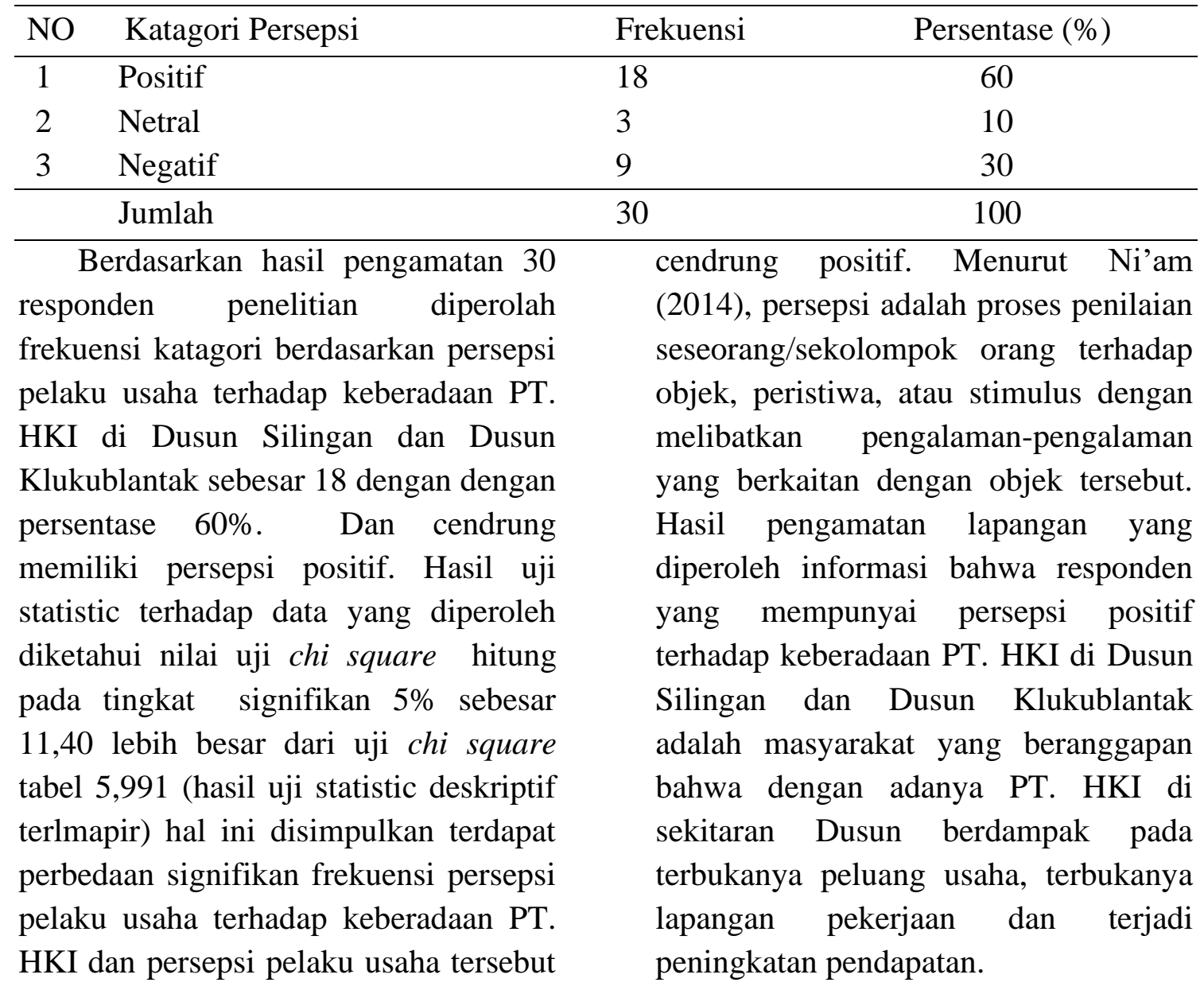

Tabel 3. Persepsi Tenaga Kerja Terhadap Keberadaan PT. HKI (Workers Perception of the Existence of PT. HKI)

\begin{tabular}{llll}
\hline NO & Katagori Persepsi & Frekuensi & Persentase (\%) \\
\hline 1 & Positif & 18 & 60 \\
2 & Netral & 2 & 6,67 \\
3 & Negatif & 10 & 33,33 \\
\hline \multicolumn{2}{c}{ Jumlah } & 30 & 100 \\
\hline \multicolumn{2}{c}{ Hasil pengamatan 30 responden } & berdasarkan persepsi tenaga kerja \\
penelitian diperolah frekuensi katagori & terhadap keberadaan PT. HKI di Dusun
\end{tabular}


Silingan dan Dusun Klukublantak Desa Mekar Utama cendrung memiliki persepsi positif yaitu dengan frekuensi 18 dengan persentase 60\%. Hasil uji statistic ( uji chi square) terhadap data yang diperoleh diketahui nilai uji chi square hitung pada tingkat signifikan
$5 \%$ sebesar 12,80 lebih besar dari uji chi square tabel 5,991 hal ini disimpulkan terdapat perbedaan signifikan frekuensi persepsi tenaga kerja terhadap keberadaan PT.HKI dan persepsi tenaga kerja tersebut cendrung positif.

Table 4. Persepsi Masyarakat Terhadap Keberadaan PT.HKI (Community Perception of the Existence of PT. HKI)

\begin{tabular}{llll}
\hline NO & Katagori Persepsi & Frekuensi & Persentase (\%) \\
\hline 1 & Positif & 16 & 53,33 \\
2 & Netral & 2 & 6,67 \\
3 & Negatif & 12 & 40 \\
\hline \multicolumn{2}{c}{ Jumlah } & 30 & 100 \\
\hline \multicolumn{2}{c}{ Hasil pengamatan 30 responden } & pemahaman yang baik terhadap suatu \\
penelitian diperoleh frekuensi katagori & kegiatan tersebut maka pembinaan yang \\
berdasarkan persepsi masyarakat dan & dilakukan tidak akan berhasil dan \\
pekerja dari luar terhadap keberadaan & mengakibatkan kegitan tersebut menjadi \\
PT. HKI di Dusun Silingan dan Dusun & gagal serta tidak bermanfaat.
\end{tabular}
Klukublantak Desa Mekar Utama cendrung memiliki persepsi positif yaitu dengan frekuensi 16 dengan persentase 53,33\%. Hasil uji statistic (uji chi square) terhadap data yang diperoleh diketahui nilai uji chi square hitung pada tingkat signifikan 5\% sebesar 10,40 lebih besar dari uji chi square tabel 5,991 hal ini disimpulkan terdapat perbedaan signifikan frekuensi persepsi tenaga kerja terhadap keberadaan PT.HKI dan persepsi tenaga kerja tersebut cendrung positif. Dari ketiga persepsi responden menyatakan bahwa keberadaan PT. HKI memberi dampak posistip terhadap ekonomi masyarakat di Dusun Silingan dan Dusun Klukulantak. Menurut Khalik (2004), persepsi masyarakat terhadap suatu kegiatan merupakan faktor penting dalam pelaksanaan kegiatan tersebut, karena tanpa adanya persepsi atau

\section{Multiplier Effect}

Adanya PT. HKI di Dusun Silingan dan Dusun klukublantak menimbulkan dampak ekonomi terhadap masyarakat sekitar. Dampak ekonomi yang muncul dari keberadaan PT. HKI yaitu dampak lansung, dampak tidak lansung dan dampak induced. Menurut agustina (2009), dampak ekonomi dari kegiatan industri atau berbagai kegiatan ekonomi dapat dikelompokkan pada tiga kategori, yaitu dampak langsung (direct), dampak tidak langsung (indirect), dan dampak lanjutan (induced). Dampak langsung ditimbulkan dari pengeluaran konsumen secara langsung, seperti pengeluaran pada restoran, penginapan, transportasi lokal dan lainnya. Selanjutnya, unit usaha yang menerima dampak langsung tersebut akan membutuhkan input (bahan baku dan tenaga kerja) dari sektor lain, dan hal ini akan menimbulkan dampak tidak langsung 
(indirect). Selanjutnya jika pada sektor tersebut mempekerjakan tenaga kerja lokal, pengeluaran dari tenaga kerja lokal akan menimbulkan dampak lanjutan (induced) di lokasi industry tersebut tersebut.

Pengukuran multipiler adalah pengaruh pengeluaran tambahan yang diperkenalkan dalam ilmu ekonomi. Hal tersebut mencakup marginal dari perubahan rata-rata, dalam kasus keberadaan PT HKI pengeluaran masyarakat dan pekerja dari luar daerah dapat berbentuk konsumsi sehari- hari di dalam kawasan. Jumlah pengeluaran masyarakat dan pekerja pendatang yang dikeluarkan selama satu bulan di dalam kawasan yaitu sebesar Rp 43.700.000

\section{Dampak Langsung}

Keberadaan PT. HKI membuka peluang bagi masyarakat sekitar untuk membuka usaha terkait dengan pemenuhan kebutuhan masyarakat dan tenaga kerja dari luar selama berada di lokasi. adapaun usaha yang ada ialah warung sembako (WS), petani madu (PM), rumah makan (RM), bengkel (BK) dan konter (KP). Seperti yang ada di tabel berikut:

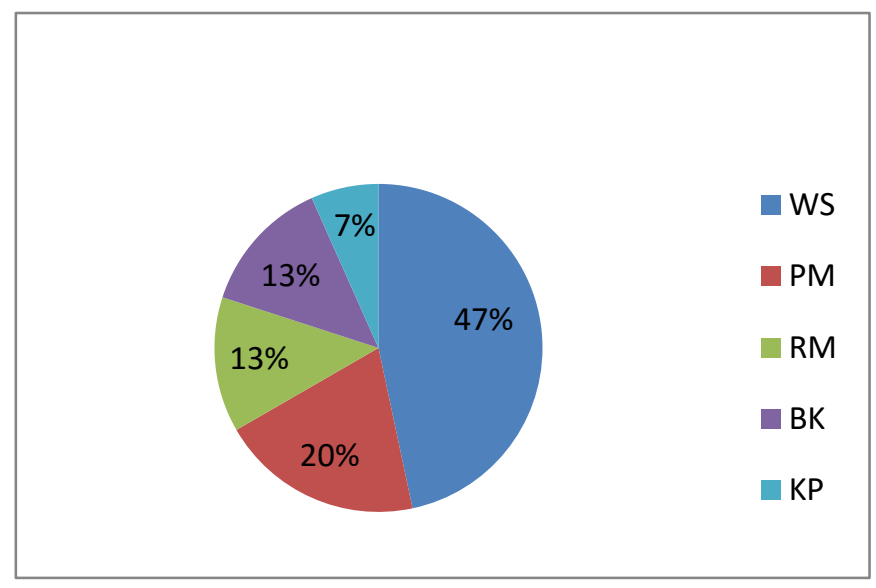

Gambar 1. Diagaram Jenis usaha Masyarakat (Diagram Type of Community Business)

Berdasarkan diagram diatas, jumlah warung sembako memiliki persentase lebih banyak dibandingkan unit usaha lainnya artinya kebutuhan pangan masyarakat tinggi sehingga jumlah warung sembakonya juga banyak. Dampak langsung adalah total pengeluaran masyarakat dan pekerja pendatang dalam melakukan pembelian kebutuhan konsumsi yang di diterima lansung oleh unit usaha yang ada disana. Pengeluaran masyarakat yang diterima langsung oleh unit usaha berupa pengeluaran untuk pembelian kebutuhan pokok dan keperluan sehari-hari dan keseluruhan unit usaha memperoleh total pendapatan sebesar Rp 109.600.000 dampak ini sangat lansung dirasakan oleh pemilik usaha terutama usaha warung sembako yang jumlahnya lebih banyak dibandingkan usaha lainnya.

\section{Dampak Tidak Lansung}

Dampak tidak langsung adalah upah tenaga kerja yang diperoleh dari bekerja pada unit usaha di sekitar kawasan PT. HKI, namun tidak semua unit usaha di kawasan PT. HKI memiliki tenaga kerja, hanya beberapa unit usaha yang memilki 
tenaga kerja yaitu peternak madu, rumah makan dan bengkel dengan jumlah keseluruhan 12 orang, para pekerja ini sangat menggantungnya pendapatannya dengan bekerja di unit usaha di sekitar kawasan PT. HKI hal ini di buktikan dengan tidak adanya pekerjaan sampingan yang dilakukan oleh tenaga kerja. Berdasarkan 30 responden tenaga kerja terdapat 12 orang tenaga kerja yang bekerja pada unit usaha dan 18 orang lainnya bekerja di PT. HKI. Hasil keseluruhan pendapatan tenaga kerja yang bekerja pada unit usaha sebesar Rp 21.100.000

\section{Dampak Lanjutan}

\section{Hasil Multiplier Effect}

Tabel 5. Hasil Analisis Multiplier Effect (Multiplier Effect Analysis Results)

Kriteria

Nilai

Keynesian 3,25

Ratio Income Multiplier 1,19

Ratio

Income

1,29

\footnotetext{
Berdasarkan data yang diperoleh untuk menentukan besarnya dampak ekonomi di PT. HKI. diperoleh nilai Keynesian Multiplier Effect yaitu sebesar 3,25 artinya setiap terjadi peningkatan pengeluaran masyarakat sebesar satu rupiah, maka akan berdampak langsung sebesar 3,25 rupiah terhadap perekonomian masyarakat sekitar. Nilai
}

Dampak lanjutan adalah pengeluaran yang dikeluarkan oleh tenaga kerja sebagai perputaran uang yang diperoleh dari dampak langsung dan dampak tidak langsung. Pengeluaran tersebut berupa pengeluaran tenaga kerja untuk pembelian konsumsi di unit usaha yang berada di dalam lokasi PT.HKI. Tenaga kerja mengeluarkan total biaya konsumsi sebesar Rp 11.200.000 Biaya yang diterima unit usaha kembali digunakan oleh unit usaha untuk membeli keperluan bahan usaha, dari rata-rata total pengeluaran tenaga kerja dikeluarkan di dalam kawasan PT. HKI.
Keterangan

Dampak ekonomi yang terjadi
memberikan dampak ekonomi yang besar
terhadap keberadaan PT.HKI karena
karena nilai Keynesian Income Multiplier
yang diperoleh lebih besar dari satu $(\geq 1)$

I Dampak ekonomi dikatakan telah memberikan dampak yang besar karena nilai Ratio Income Multiplier Tipe I dan Ratio Income Multiplier Tipe II adalah I lebih besar atau sama dengan satu $(\geq 1)$. 
peningkatan sebesar satu rupiah pada penerimaan unit usaha maka akan mengakibatkan peningkatan sebesar 1,29 rupiah pada dampak lansung, tidak lansung dan induced.

Dampak ekonomi yang terjadi pada penelitian ini dikatakan sangat tinggi, dapat dilihat dari nilai Keynesian Income Multiplier yang diperoleh yaitu sebesar 4,88, hal ini disebabkan besarnya jumlah pendapatan dari pelaku usaha yang di terima lansung dari pengeluaran masyarakat dan pekerja pendatang. Jika dibandingkan dengan penelitian Mutiarani (2011), hasil penelitian menunjukan bahwa tingkat multiplier effect di lokasi rekreasi situbondoh sangat tinggi hasil ini bisa di lihat dari nilai Keynesian Income Multiplier adalah 4,04, Ratio Income Multiplier Tipe 1 adalah 1,08 dan Ratio Income Multiplier Tipe 2 adalah 1,16, dengan demikian multiplier yang dihasilkan dari rekreasi situbondoh memiliki efek berganda yang baik karena memiliki nilai yang lebih dari 1 , hasil penelitian tersebut juga di dukung dari hasil penelitian Milasari (2010), yang menunjukan bahwa keberadaan taman wisata tirta sanita menimbulkan efek berganda terhadap pendapatan masyarakat yang berada di sekitar kawasan, hasil ini dapat di lihat dari nilai Keynesian Income Multiplier adalah 1,07, Ratio Income Multiplier Tipe I adalah 1,22, dan Ratio Income Multiplier Tipe II adalah 1,37. Dari beberapa penelitian yang sudah dilakukan sebelumnya pengeluaran pengunjung sangat berpengaruh kepada pendapatan pengelola wisata, pelaku usaha dan tenaga kerja yang ada di lokasi wisata sedangkan dalam penelitian ini pengeluaran masyarakat dan pekerja pendatang hanya berpengaruh kepada pendapatan pelaku usaha dan tenaga kerja dan tidak berpengaruh kepada pihak PT. HKI. Kondisi tersebut sesuai dengan teori basis ekonomi menurut Arsyad (2010), menyatakan bahwa faktor penentu utama pertumbuhan ekonomi suatu daerah yaitu berhubungan langsung dengan permintaan barang dan jasa dari konsumen.

Adanya PT. HKI memudahkan masyarakat untuk membuka usaha dan mendapatkan pekerjaan hal ini diperkuat dari pendapat Yamani (2017), secara umum bahwa dengan adanya kawasan perkebunan PT. HKI telah menyebabkan munculnya sumber-sumber pendapatan rumah tangga masyarakat baru yang bervariasi. Sebelum dibukanya kawasan PT. HKI di Desa Kedondong, sumber pendapatan rumah tangga masyarakat relative homogen, yakni menggantungkan hidupnya pada sektor primer, memanfaatkan sumberdaya alam yang tersedia seperti apa adanya tanpa penggunaan teknologi yang berarti. Pembangunan perkebunan Hutan Tanaman Industri PT. HKI mempunyai pengaruh terhadap Pendapatan Rumah Tangga Masyarakat di wilayah perkebunan, yaitu dapat menciptakan lapangan usaha baru seperti membuka usaha sembako, membuka usaha mebel, membuka usaha menjahit, warung makan, warung es, kios bbm. Sedangkan Hasil penelitian sebelum adanya PT. HKI di Dusun Silingan dan Dusun Klukublantak jumlah usaha sebanyak 9 unit usaha dengan kebutuhan yang terbatas dan 
setelah adanya PT. HKI jumlah unit usaha di kedua Dusun bertambah menjadi 21 unit, diantaranya warung sembako, peternak madu, rumah makan, bengkel, dan konter pulsa.

\section{KESIMPULAN}

Hasil penelitian yang telah dilakukan di Dusun Silingan dan Dusun Kelukub Desa Mekar Utama Kecamtan Kendawangan Kabupaten Ketapang dapat disimpulkan sebagai berikut

1. Karakteristik pelaku usaha yang ada di PT. HKI lebih banyak jumlah laki-laki di bandingkan perempuan begitu juga dengan tenaga kerja jumlah laki-laki lebih banyak dibandingkan peremnpuan. Jumlah jenis usaha yang paling banyak dikedua Dusun yaitu warung sembako dengan proporsi $46,67 \%$.

2. Persepsi pelaku usaha, tenaga kerja dan masyarakat terhadap keberadaan PT. HKI cenderung memiliki persepsi positif, dengan persentase dari masing-masing persepsi yaitu persepsi pelaku usaha $60 \%$, persepsi tenaga $60 \%$ dan persepsi masyarakat 53,33\%.

3. Dampak ekonomi yang terjadi pada penelitian ini dikatakan sangat tinggi, dapat dilihat dari nilai Keynesian Income Multiplier yang diperoleh yaitu sebesar 3,25 apabila nilai Keynesian Income Multiplier yang diperoleh lebih besar dari satu $(\geq 1)$ maka keberadaan PT. HKI tersebut memiliki dampak ekonomi yang tinggi Sedangkan Ratio Income Multiplier Tipe 1 sebesar 1,19 dan Ratio Income Multiplier Tipe 2 sebesar 1,29 dapat dikatakan telah memberikan dampak ekonomi terhadap keberadaan PT. HKI karena nilai Ratio Income Multiplier Tipe 1 dan Tipe 2 sudah lebih besar atau sama dengan satu $(\geq 1)$.

\section{SARAN}

Adapun beberapa saran yang perlu diperhatian bagi peneliti selanjutnya yang tertarik meneliti tentang multiplier effect PT. Hutan Ketapang Industri terhadap Usaha masyarakat yaitu:

1. Peneliti selanjutnya diharapkan untuk menentukan jumlah responden pekerja pendatang lebih banyak dari jumlah responden pelaku usaha supaya nilai ekonomi yang dihasilkan tidak telalu besar.

2. Peneliti selanjutnya diharapkan untuk menghitung kebocoran uang yang terjadi di kawasan PT. HKI yang diakibatkan dari pengeluaran pekerja pendatang untuk belanja kebutuhan konsumsi diluar kawasan.

\section{UCAPAN TERIMAKASIH}

Terimakasih disampaikan kepada pihak PT. HKI yang senantiasa memberi dukungan dan memberi masukan serta memfasilitasi mahasiswa dalam melakukan penelitian dari mulai pemberangkatan, keperluan alat penelitian dan transportasi dilapangan. Sehingga penulisan ini dapat diselesaikan dengan maksimal.

\section{DAFTAR PUSTAKA}

Agustina VS. 2009. Analisis persepsi dan referensi pengunjung serta dampak ekonomi kegiatan wisata Gunung Salak Endah [skripsi]. Bandung: Institut Pertanian Bogor. 
Arsyad L. 2010. Ekonomi Pembangunan, Edisi 5. Yogyakarta : UPP STIM YKPN.

Domanski, Boleslaw G, Krzysztof. 2010. Multipliler Effect In local and Regional Development. Quaestiones Geographicae. Adam Mickiewics University Press: Poznan.

Dristato A, Anissa AA. 2013. Analisis Dampak ekonomi Wisata Bahari Terhadap Pendapatan Masyarakat di Pulau Tindung. Reka Lokajurnal Online Institut Teknologi Nasional 20.(10):2-3

Hasanah EU,Sunyoto D. 2012. pengantar Ilmu Ekonomi Makro. Yogyakarta: CPAS.

Khalik A A. 2004. Partisipasi Masyarakat Perserta Reboisasi Terhadap Kegiatan Pasca Program Reboisasi Di Desa Sejauh Kecamatan Kembayan Kabupaten Sanggau [Skripsi]. Pontianak : Fakultas Kehutanan. Universitas Tanjungpura.

Menteri Kehutanan Nomor : P.62/MenhutII/2008 tangal 6 November 2008 tentang Rencana Kerja Tahunan.

Milasari HA. 2010. Dampak Ekonomi Wisata Taman Wisata Tirta Sanita. Bandung: Institut Pertanian Bogor.

Mutiarani N. 2011. Dampak Ekonomi dan Nilai Ekonomi Manfaat Rekreasi Situ Cipondoh Tangerang. Bandung: Institut Pertanian Bogor.

Ni'am AL, Mussadun. 2014. Dampak Aktivitas Ekowisata Di Pulau Karimunjawa Berdasarkan Persepsi Masyarakat. Jurnal Teknik PWK 3.(2):262-273.

www.portalgaruda.com. Diakses: 24 Januari 2018.
Sholihin, ahmad I. 2010. Buku Pintar Ekonomi Syariah. Jakarta: Gramedia pustaka utama.

Sugiyono. 2011. Metode Penelitian Kuantitatif, Kualitatif dan R \& D. Bandung: Afabeta.

Sukirno, Sadono. 2012. Makro Ekonomi Pembangunan Dari Klasik Hingga Keynesian Baru. Jakarta: PT. Raja Grapindo.

Yamani A, Kusrini N, Komariati. 2017. Pengaruh Keberadaan PT. Hutan Ketapang Industri Terhadap Pendapatan Rumah Tangga Masyarakat. Jurnal Social Economic of Agriculture 6. 